\title{
Kamu Harcamalarının Ekonomik Büyüme Üzerine Etkisi: 1990-2017 Türkiye Örneği (The Impact of Public Expenditure on Economic Growth: 1990-2017 Case of Turkey)
}

\author{
Murat TEKBAŞ iD a \\ a Afyon Kocatepe Üniversitesi, Bayat Meslek Yüksekokulu, Afyonkarahisar, Türkiye, mtekbas@aku.edu.tr
}

\begin{tabular}{|c|c|}
\hline MAKALE BİLGİsí & ÖZET \\
\hline Anahtar Kelimeler: & $\begin{array}{l}\text { Amaç - Bu çalışmanın amacı kamu harcamalarının ekonomik büyüme üzerindeki etkisinin 1990- } \\
2017 \text { yılları arasındaki dönemde farklı yöntemlerle Türkiye için incelenmesidir. }\end{array}$ \\
\hline Imu Harcaması & Yöntem - Çalıșmanın ilk bölümünde ilgili konu ile ilgili kavramsal açılama ve literatür özeti \\
\hline Ticari Açıklık & sunulmaktadır İkinci çalışmada kapsamında oluşturulan model ve kullanılacak yöntem hakkında \\
\hline Sermaye & bilgi verilmektedir. Üçüncü bölümde ise kamu harcamalarının ve ticari açılığın, bağımlı değişken \\
\hline Emek & $\begin{array}{l}\text { GSYH üzerindeki etkisi Gregory-Hansen eşbütünleşme testi ve ARDL sinır testi aracillğıyla } \\
\text { incelenmiştir. Ayrıca, ampirik modelin Cobb-Douglas üretim fonksiyonuna dayalı olarak }\end{array}$ \\
\hline $\begin{array}{l}\text { Gönderilme Tarihi } 23 \text { Mayıs } \\
2019\end{array}$ & $\begin{array}{l}\text { kurulması nedeniyle sermaye ve emek değişkeni de modele bağımsız değişken olarak dahil } \\
\text { edilmiştir. Çalışmada kullanılan veriler Dünya Bankası veri tabanından elde edilmiştir. }\end{array}$ \\
\hline Revizyon Tarihi 21 Ekim 2019 & Bulgular ve Tartışma - Çalışmada elde edilen bulgular sonucunda uzun ve kısa dönemde kamu \\
\hline Kabul Tarihi 25 Ekim 2019 & $\begin{array}{l}\text { harcamalarının, sermayenin birikiminin ve emeğin milli gelir üzerinde etkisinin pozitif olduğu, } \\
2007 \text { 'de yaşanan kırılmanın uzun ve kısa dönemde GSYH üzerindeki etkisinin negatif ve istatiksel }\end{array}$ \\
\hline Makale Kategorisi: & olarak anlamlı olduğu görülmüştür. Ayrıca kısa dönemde kamu harcamaları ve ticari açılıktan \\
\hline Araştırma Makalesi & $\begin{array}{l}\text { GSYH doğru nedensellik olmadığı, sermaye birikimi ve emekten GSYH doğru tek yönlü } \\
\text { nedensellik olduğu, uzun dönemde ise sermaye birikimi, emek ve GSYH arasında çift yönlü, ticari } \\
\text { açıklık ve kamu harcamasından GSYH'e doğru tek yönlü nedensellik ilişkisi olduğu sonucuna } \\
\text { ulaşılmıştır. }\end{array}$ \\
\hline ARTICLE INFO & ABSTRACT \\
\hline Keywords: & Purpose - The aim of this work in the period between 1990-2017 years of the impact on economic \\
\hline Economic Growth & \\
\hline Goverment Expenditure & Design/methodology/approach - In the first part of the study, conceptual explanation and \\
\hline Trade Openness & literature summary about the subject is presented. In the second study, information about the \\
\hline Capital & model and the method to be used is given. In the third part, the effect of public expenditures and \\
\hline Labor & trade deficit on dependent variable GDP was examined by Gregory-Hansen cointegration test and \\
\hline $\begin{array}{l}\text { Received } 23 \text { May } 2019 \\
\text { Revised } 21 \text { October }\end{array}$ & $\begin{array}{l}\text { ARDL limit test. In addition, since the empirical model is based on the Cobb-Douglas production } \\
\text { function, capital and labor are included as independent variables. The data used in the study were } \\
\text { obtained from World Bank development indicators.. }\end{array}$ \\
\hline Accepted 25 October & $\begin{array}{l}\text { Results and Discussion - As a result of the findings obtained in the study, it was observed that the } \\
\text { effect of public expenditures, capital accumulation and labor on national income were positive in } \\
\text { the long and short term, and the effect of break in } 2007 \text { on GDP in the long and short term was }\end{array}$ \\
\hline Article Classification: & negative and statistically significant. In addition, in the short run, there is no causality from public \\
\hline Research Article & $\begin{array}{l}\text { expenditures and trade openness to GDP, one-way causality from capital accumulation and labor } \\
\text { to GDP, and in the long run, one-way causality between capital accumulation, labor and GDP, } \\
\text { bidirectional, commercial openness and public spending to GDP has been concluded. }\end{array}$ \\
\hline
\end{tabular}

\section{Giriş}

Ekonomi literatüründe geçmişten günümüze süregelen en büyük tartısma devletin ekonomideki konumudur. İktisadi görüşlerin hemen hemen hepsinde oluşturulan ekonomik model içerisinde devletin yerinin ne olacağı konusuna açılık getirilmeye çalışılmış, devletin konumuna göre politikalar oluşturulmuştur. İktisadın kurucusu olarak kabul edilen A.Smith'e göre devlet iktisadi faaliyetler içerisinde sadece düzenleyici olarak yer almalı, piyasa kendi dinamiklerine göre hareket etmelidir. Bu görüş dönemsel olarak büyük kabul görmüş ve yaygın bir şekilde kullanılmıştır. Ancak tüm dünyayı etkileyen Büyük Buhran karşısında Klasik düşüncenin krize karşı çözüm üretememesi devletin ekonomideki rolünün tekrar sorgulanmasını sağlamıştır. Bu dönemde krizden çıkabilmek için Keynes, kamunun piyasa da etkin rol 
almasını, kamu harcamalarının artırarak ekonominin düzeltebileceğini öne sürmüştür. Bu doğrultuda ekonomik büyümenin sağlanabilmesi için kamunun ekonomideki rolünün ne olması gerektiği hususundaki tartışmalar devam etmektedir. Bu doğrultuda ülkelere göre farklılıklar bulunmasına rağmen ekonomik büyüme ve refah artışının sağlanmasında kamu harcamalarının neden mi yoksa sonuç mu olduğu konusu güncelliğini korumaktadır.

Söz konusu bilgiler ışığında bu çalışmada kamu harcamaları ve ekonomik büyüme arasındaki ilişki Türkiye için 1990-2017 yılları arasındaki dönem çerçevesinde incelenmiştir. Çalışmada oluşturulan modelin CobbDouglas üretim fonksiyonu temel alınarak oluşturulması nedeniyle, bağımsız değişkenler emek, sermaye, kamu harcamaları ve ticari açıklı̆̆ın bağımlı değişken olan ekonomik büyüme üzerindeki etkisi incelenmiştir. Çalışmada kurulan modelin Cobb-Douglas üretim fonksiyonuna dayanması ve kamu harcamalarının yanında ticari açıklğında bağımlı değişken olan ekonomik büyüme üzerindeki etkisinin incelenmesi çalışmayı diğer çalışmalardan farklılaştırmaktadır.

Çalışma beş bölümden oluşmakta ve ilk bölüm olan girişte, konu hakkında genel bilgiler verilmiş, ikinci bölümde konu ile literatürün özeti sunulmuş, üçüncü bölümde model, veri ve metodoloji hakkında açıklamalarda bulunulmuştur. Dördüncü bölümde konu kapsamında yapılan analizler bulunmaktadır. Analizlerde ilk olarak serilerin durağanlığını tespit etmek için Ng-Perron ve yapısal kırılmaya izin veren Zivot-Andrews birim kök testleri uygulanacaktır. Seriler arasında eşbütünleşme ilişkisi incelenirken de yapısal kırılmaları göz ardı etmemek için Gregory-Hansen eşbütünleşme testinden faydalanılacak ayrıca ARDL sınır testi uygulanacaktır. Daha sonra, değişkenler arasındaki nedenselliğin tespit edilmesi için VECM Granger nedensellik testi uygulanacaktır. Beşinci bölüm olan sonuç bölümünde ise elde edilen sonuçlara göre Türkiye için politika önerilerinde bulunulmuştur.

\subsection{Konuyla İlgili Kavramsal/Kuramsal Çerçeve}

1929 yılında meydana gelen Büyük Buhran sonrasında klasik iktisadi düşüncenin krizden çıkabilmek adına etkili bir çözüm sunamaması karşısında krizden çıabilmek için J.M. Keynes'in ortaya attı̆̆ı fikir devletin maliye ve para politikaları aracıllğıyla ekonomiye müdahalesinin gerekli olduğu yönünde olmuştur. Keynes'e göre devlet kamu harcamaları ile ekonominin bir aktörü olmalı ve ekonomik istikrarı sağlamalıdır. Klasik görüşü savunan iktisatçıların kamu harcamalarının verimsiz ve etkin olmadığı düşüncesine karşılık Keynes, ekonomide istikrarın sağlanmasında ve ekonomik büyümenin gerçekleşmesinde kamu harcamalarının itici güç olduğu düşüncesini savunmaktadır.

Ekonomik büyümenin sağlanmasında kamu harcamalarının itici güç olduğunu kabul eden görüşler, kendi içinde eğitim ve sağlık gibi alanlardaki yatırımların arttırılması sayesinde beşeri sermayenin geliştirilmesine, savunma ve güvenlik teknolojileri alanındaki gelişmeler sayesinde dış ticaretin geliştirilmesine kadar kamu harcamalarının farklı boyutlarını önemli görmüşlerdir. Kamunun yapmış olduğu harcamaların ekonomik büyüme üzerindeki olumlu etkisi savunulmakla birlikte kamu harcamalarının sonucunda ekonomik büyümenin gerçekleşeceği, ekonomik büyüme sonucunda kamu harcamalarının artacağı noktasında iki ayrı yaklaşım bulunmaktadır. Bu görüşlerden ilki kamu harcamalarını içsel gören Wagner'e aittir. Wagner'e göre devlet, ekonomik büyümeyi belirli bir olgunluk düzeyine ulaştırdığında ortaya çıkacak ihtiyaçlar nedeniyle kamu harcamalarında artışa gidecektir. Kısacası, Wagner'e göre kamu harcamaları ekonomik büyümenin sonucudur. İkinci görüş ise Keynes'e ait olup; bu görüşe göre, devletin ekonomik büyümeyi gerçekleştirmesi için kamu harcamaları yapması gerekmektedir. Keynes, kamu harcamalarını ekonomik büyümenin sonucu olarak değil, nedenlerinden biri olarak görmektedir.

Çalışmada, Türkiye'de 1990-2017 yılları arasındaki dönemde kamu harcamaları ve ekonomik büyüme arasındaki ilişki, Wagner ve Keynes'e ait iki yaklaşım kapsamında incelenecektir. Bu iki yaklaşım kapsamında ekonomik büyümeden kaynaklanan ihtiyaçlar nedeniyle mi kamu harcamalarında artış yaşandığı, yoksa kamu harcamalarında meydana gelen artış nedeniyle mi ekonomik büyümenin sağlandığı incelenmeye çalışılacaktır.

\subsection{Literatür Taramas1}

Ekonomi literatüründe kamu harcaması ve ekonomik büyüme ilişkisinin incelendiği birçok çalışma olduğu görülmektedir. Çalı̧̧maların bir bölümünde ülke bazlı zaman serilerinin kullanılarak analiz yapıldığı, diğer çalışmalarda ise birden fazla ülke için panel veri analizi kullanıldığı görülmektedir. Çalışmalar sonuç 
yönünden değerlendirildiğinde ortak bir sonuca ulaşılamadığı, çalışmaların bir kısmında kamu harcamalarının ekonomik büyümeyi artırdığı, bir kısmında ise kamu harcamalarının ekonomik büyümeyi azalttığ1 görülmüştür. Ayrıca literatürde kamu harcaması ve ekonomik büyüme arasında ilişki olmadığ1 tespit edilen çalışmalar da bulunmaktadır.

Literatürdeki çalışmalar incelendiğinde, çalışmaların büyük bölümünde toplam kamu harcamalarının değerlendirildiği, bazı çalışmalarda ise farklı kamu harcama türlerinin ekonomik büyüme ile olan ilişkisinin incelendiği görülmüştür. Çalışmamızda yapılan literatür incelemesi Türkiye üzerine yapılan zaman serisi analizleri ağırlıklı olmak üzere, panel çalışmaları da kapsamaktadır.

Tablo 1: Kamu Harcaması ile ekonomik büyüme arasındaki ilişkiye dair ampirik literatür özeti

\begin{tabular}{llll} 
Çalışma & Veri & Yöntem & Sonuç \\
\hline $\begin{array}{l}\text { Afşar } \\
(2009)\end{array}$ & $\begin{array}{l}\text { 1963-2005 } \\
\text { Türkiye }\end{array}$ & $\begin{array}{l}\text { Granger } \\
\text { Nedensellik Testi }\end{array}$ & $\begin{array}{l}\text { Ekonomik büyüme ve eğitim harcamaları } \\
\text { arasında çift yönlü ilişki bulunmuştur. }\end{array}$ \\
\hline $\begin{array}{l}\text { Erdoğan ve } \\
\begin{array}{l}\text { Yıldırım } \\
(2009)\end{array}\end{array}$ & $\begin{array}{l}\text { 1983-2005 } \\
\text { Türkiye }\end{array}$ & ARDL sınır Testi & $\begin{array}{l}\text { Eğitim harcamaları İlkokul düzeyinde } \\
\text { ekonomik büyümeyi pozitif, lise ve } \\
\text { yükseköğretim düzeyinde ise negatif } \\
\text { etkilemektedir. }\end{array}$ \\
\hline
\end{tabular}

\begin{tabular}{|c|c|c|c|}
\hline $\begin{array}{l}\text { Yumuşak ve } \\
\text { Yildırım } \\
\text { (2009) }\end{array}$ & $\begin{array}{l}1980-2005 \\
\text { Türkiye }\end{array}$ & $\begin{array}{l}\text { VECM } \\
\text { Nedensellik Testi }\end{array}$ & $\begin{array}{l}\text { Sağlık harcamalarınin ekonomik büyümeyi } \\
\text { negatif etkilediği görülmüştür. }\end{array}$ \\
\hline $\begin{array}{l}\text { Verma ve } \\
\text { Arora } \\
(2010) \\
\end{array}$ & $\begin{array}{l}\text { 1950-2008 } \\
\text { Hindistan }\end{array}$ & $\begin{array}{l}\text { VECM } \\
\text { Nedensellik Testi }\end{array}$ & $\begin{array}{l}\text { Ekonomik büyümenin kamu harcamalar } \\
\text { üzerinde pozitif etkisi olduğu görülmüştür. }\end{array}$ \\
\hline
\end{tabular}

\begin{tabular}{|c|c|c|c|}
\hline $\begin{array}{l}\text { Çetin ve } \\
\text { Ecevit } \\
(2010)\end{array}$ & $\begin{array}{l}1990-2006 \\
\text { OECD Ülkeleri }\end{array}$ & OLS & $\begin{array}{l}\text { Sağlık harcamaları ve ekonomik büyüme } \\
\text { arasında ilişki olmadığı görülmüştür. }\end{array}$ \\
\hline $\begin{array}{l}\text { Tan vd., } \\
(2010)\end{array}$ & $\begin{array}{l}1969-2003 \\
\text { Türkiye }\end{array}$ & $\begin{array}{l}\text { VAR Granger } \\
\text { Nedensellik Testi } \\
\text { Toda Yamamoto } \\
\text { Nedensellik Testi }\end{array}$ & $\begin{array}{l}\text { Altyapı harcamalarından ekonomik } \\
\text { büyümeye tek yönlü, eğitim ve altyapı } \\
\text { harcamaları arasında ise çift yönlü ilişki } \\
\text { görülmüştür. }\end{array}$ \\
\hline $\begin{array}{l}\text { Çalışkan vd., } \\
\text { (2013) }\end{array}$ & $\begin{array}{l}1923-2011 \\
\text { Türkiye }\end{array}$ & $\begin{array}{l}\text { Johansen } \\
\text { Eşbütünleşme } \\
\text { Testi }\end{array}$ & $\begin{array}{l}\text { İlkokul öğrenci sayısı ile ekonomik büyüme } \\
\text { arasında negatif, lise ve yükseköğretim } \\
\text { öğrenci sayısı ile ekonomik büyüme } \\
\text { arasında pozitif ilişki olduğu görülmüştür. }\end{array}$ \\
\hline $\begin{array}{l}\text { Selim vd., } \\
(2014)\end{array}$ & $\begin{array}{l}\text { 2001-2011 } \\
\text { AB üyesi } 27 \text { ülke }\end{array}$ & $\begin{array}{l}\text { Westerlund Panel } \\
\text { Eşbütünleşme } \\
\text { PMG tahmincisi }\end{array}$ & $\begin{array}{l}\text { Ekonomik büyüme üzerinde sağlık } \\
\text { harcamalarının negatif etkili olduğu tespit } \\
\text { edilmiştir. }\end{array}$ \\
\hline $\begin{array}{l}\text { Pamuk ve } \\
\text { Bektaş } \\
(2014) \\
\end{array}$ & $\begin{array}{l}\text { 1998:01-2013:02 } \\
\text { Türkiye }\end{array}$ & ARDL Sinır Testi & $\begin{array}{l}\text { Eğitim harcamalarından } \\
\text { büyümeye doğru tek yönlü nedensellik } \\
\text { ilişkisi görülmüştür. }\end{array}$ \\
\hline $\begin{array}{l}\text { Arin, vd., } \\
(2015)\end{array}$ & $\begin{array}{l}\text { 1990-2009 } \\
\text { OECD }\end{array}$ & $\begin{array}{l}\text { Bayesian Panel } \\
\text { Data Modeli }\end{array}$ & $\begin{array}{l}\text { Kamu harcamalarının ekonomik büyümeyi } \\
\text { pozitif etkilediği sonucu elde edilmiştir. }\end{array}$ \\
\hline $\begin{array}{l}\text { Bekmez, ve } \\
\text { Destek } \\
(2015)\end{array}$ & $\begin{array}{l}\text { 1988-2012 } \\
\text { Azgelişmiş - } \\
\text { Gelişmekte ve Gelişmiş } \\
\text { ülkeler }\end{array}$ & $\begin{array}{l}\text { Panel Veri } \\
\text { Regresyon Analizi }\end{array}$ & $\begin{array}{l}\text { Savunma harcamalarının ekonomik } \\
\text { büyüme üzerinde pozitif etkili tespit } \\
\text { edilmiştir. }\end{array}$ \\
\hline $\begin{array}{l}\text { Ahmad ve } \\
\text { Masan } \\
(2015)\end{array}$ & $\begin{array}{l}\text { 1971-2013 } \\
\text { Umman }\end{array}$ & $\begin{array}{l}\text { Johansen } \\
\text { Eşbütünleşme } \\
\text { VECM Granger } \\
\text { Testi }\end{array}$ & $\begin{array}{l}\text { Kamu harcamalarının ekonomik büyümeyi } \\
\text { pozitif etkilediği sonucu elde edilmiştir. }\end{array}$ \\
\hline
\end{tabular}




\begin{tabular}{|c|c|c|c|}
\hline $\begin{array}{l}\text { Esen ve } \\
\text { Bayrak } \\
(2015)\end{array}$ & $\begin{array}{l}\text { 1990-2012 } \\
\text { Azerbaycan,Kazakistan, } \\
\text { Kırg1zistan, Özbekistan, } \\
\text { Türkmenistan }\end{array}$ & $\begin{array}{l}\text { Westerlund Panel } \\
\text { Eşbütünleşme, } \\
\text { DOLS }\end{array}$ & $\begin{array}{l}\text { Kamu harcamalarının, ekonomik büyüme } \\
\text { üzerinde pozitif etkili olduğu sonucuna } \\
\text { ulaşılmıştır. }\end{array}$ \\
\hline $\begin{array}{l}\text { Banegas ve } \\
\text { Rivero } \\
(2016)\end{array}$ & $\begin{array}{l}\text { 1993-2012 } \\
\text { Bolivya }\end{array}$ & $\begin{array}{l}\text { OLS, RLS, GLM, } \\
\text { SLS, VAR } \\
\text { Granger } \\
\text { Nedensellik Testi }\end{array}$ & $\begin{array}{l}\text { Kamu harcamalarının ekonomik büyümeyi } \\
\text { olumsuz etkilediği görülmüştür. }\end{array}$ \\
\hline $\begin{array}{l}\text { Başar vd., } \\
(2016)\end{array}$ & $\begin{array}{l}\text { 1998:1 - 2016:1 } \\
\text { Türkiye }\end{array}$ & $\begin{array}{l}\text { ARDL Sinır Testi } \\
\text { VECM Granger } \\
\text { Nedensellik Testi }\end{array}$ & $\begin{array}{l}\text { Eğitim harcamaları ve ekonomik büyüme } \\
\text { arasındaki ilişki bulunmadığı ve sağlık } \\
\text { harcamalarının ekonomik büyümeyi pozitif } \\
\text { etkilediği sonucu elde edilmiştir. }\end{array}$ \\
\hline $\begin{array}{l}\text { Diler } \\
(2016)\end{array}$ & $\begin{array}{l}\text { 1998-2010 } \\
\text { Türkiye }\end{array}$ & $\begin{array}{l}\text { ARDL Sinir Testi } \\
\text { Toda-Yamamoto } \\
\text { Nedensellik Testi }\end{array}$ & $\begin{array}{l}\text { Kamu harcamaları ve ekonomik büyüme } \\
\text { arasında ilişki bulunmamıştır. }\end{array}$ \\
\hline $\begin{array}{l}\text { Telek ve } \\
\text { Telek } \\
(2016)\end{array}$ & $\begin{array}{l}\text { 1998-2015 } \\
\text { Türkiye }\end{array}$ & $\begin{array}{l}\text { VAR Granger } \\
\text { Nedensellik Testi }\end{array}$ & $\begin{array}{l}\text { Kamu harcamalarından } \\
\text { büyümeye doğru tek yönlü } \\
\text { tespit edilmiştir. }\end{array}$ \\
\hline $\begin{array}{l}\text { Murthy ve } \\
\text { Okunade } \\
\text { (2016) }\end{array}$ & $\begin{array}{l}\text { 1960-2012 } \\
\text { ABD }\end{array}$ & ARDL Sinır Testi & $\begin{array}{l}\text { Sağlık harcamalarının ekonomik büyüme } \\
\text { üzerinde pozitif etkili olduğu görülmüştür. }\end{array}$ \\
\hline $\begin{array}{l}\text { Abdiyeva ve } \\
\text { Çetintaş } \\
(2017)\end{array}$ & $\begin{array}{l}\text { 1995-2014 } \\
\text { Kirgizistan }\end{array}$ & $\begin{array}{l}\text { ARDL Sınır Testi } \\
\text { VECM Granger } \\
\text { Nedensellik Testi } \\
\end{array}$ & $\begin{array}{l}\text { Ekonomik büyüme ve kamu harcamaları } \\
\text { arasında tek yönlü ilişki tespit edilmiştir. }\end{array}$ \\
\hline $\begin{array}{l}\text { Artan, vd. } \\
(2017)\end{array}$ & $\begin{array}{l}\text { 1996-2015 } \\
\text { Gelişmiş ve } \\
\text { Gelişmekte olan }\end{array}$ & $\begin{array}{l}\text { Panel Veri } \\
\text { Regresyon Analizi }\end{array}$ & $\begin{array}{l}\text { Kamu kesimi büyüklüğünün incelenen } \\
\text { ülkelerde ekonomik büyümeyi negatif } \\
\text { etkilediği görülmüştür. }\end{array}$ \\
\hline $\begin{array}{l}\text { Durmuş } \\
(2017)\end{array}$ & $\begin{array}{l}\text { Türkiye, Azerbaycan, } \\
\text { Ermenistan, İran, } \\
\text { Güney Kıbris }\end{array}$ & $\begin{array}{l}\text { Westerlund ve } \\
\text { Edgerton } \\
\text { Eşbütünleşme } \\
\text { CCE tahmincisi }\end{array}$ & $\begin{array}{l}\text { Eğitim harcamaları ve ekonomik büyüme } \\
\text { arasındaki ilişkinin Türkiye ve İran'da } \\
\text { pozitif, Güney Kıbrıs'da negatif, } \\
\text { Azerbaycan ve Ermenistan'da ise anlamsız } \\
\text { olduğu görülmüştür. }\end{array}$ \\
\hline $\begin{array}{l}\text { Eğri vd., } \\
(2017)\end{array}$ & $\begin{array}{l}\text { 1970-2012 } \\
\text { Türkiye ve seçilmiş } \\
\text { Ortadoğu ülkeleri }\end{array}$ & $\begin{array}{l}\text { Panel Veri } \\
\text { Regresyon Analizi }\end{array}$ & 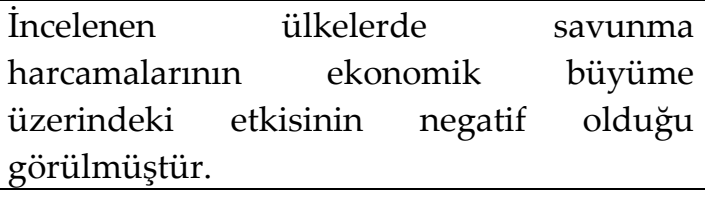 \\
\hline $\begin{array}{l}\text { Kiraz, ve } \\
\text { Gümüş } \\
(2017)\end{array}$ & $\begin{array}{l}\text { 1998-2011 } \\
29 \text { OECD ülkesi }\end{array}$ & $\begin{array}{l}\text { Panel Granger } \\
\text { Nedensellik Testi }\end{array}$ & $\begin{array}{l}\text { Ekonomik büyümeden savunma, eğitim, } \\
\text { sağlık harcamalarına tek yönlü nedensellik } \\
\text { ilişkisi tespit edilmiştir. }\end{array}$ \\
\hline $\begin{array}{l}\text { Kolçak, vd. } \\
(2017)\end{array}$ & $\begin{array}{l}\text { 1984-2014 } \\
\text { Türkiye }\end{array}$ & $\begin{array}{l}\text { FMOLS } \\
\text { tahmincisi } \\
\text { VECM Granger } \\
\text { Nedensellik Testi }\end{array}$ & $\begin{array}{l}\text { Kamu harcamalarının ekonomik büyümeyi } \\
\text { arasında ilişki olmadığı görülmüştür. }\end{array}$ \\
\hline $\begin{array}{l}\text { Tülümce ve } \\
\text { Zeren } \\
\text { (2017) }\end{array}$ & $\begin{array}{l}\text { 1975-2014 } \\
\text { Türkiye }\end{array}$ & $\begin{array}{l}\text { Hacker-Hatemi J } \\
\text { Nedensellik Testi }\end{array}$ & $\begin{array}{l}\text { Kamu ve transfer harcamaları ile ekonomik } \\
\text { büyüme arasında çift yönlü nedensellik } \\
\text { ilişkisi görülmüştür. }\end{array}$ \\
\hline $\begin{array}{l}\text { Çalışkan, vd. } \\
\text { (2018) }\end{array}$ & $\begin{array}{l}\text { 1998:01 - 2016:02 } \\
\text { Türkiye }\end{array}$ & $\begin{array}{l}\text { Maki } \\
\text { Eşbütünleşme } \\
\text { Testi, FMOLS } \\
\text { Tahmincisi }\end{array}$ & $\begin{array}{l}\text { Ĕgitim, sağlık, sosyal hizmet harcamalarının } \\
\text { ekonomik büyümeyi pozitif etkilediği } \\
\text { sonucuna ulaşılmıştır. }\end{array}$ \\
\hline $\begin{array}{l}\text { Kizll ve } \\
\text { Ceylan } \\
\text { (2018) }\end{array}$ & $\begin{array}{l}\text { 1979-2015 } \\
\text { Türkiye }\end{array}$ & $\begin{array}{l}\text { ARDL Sinir Testi } \\
\text { FMOLS, DOLS, } \\
\text { CCR tahmincisi }\end{array}$ & $\begin{array}{l}\text { Sağlık harcamalarının ekonomik büyüme } \\
\text { üzerinde pozitif etkili olduğu görülmüştür. }\end{array}$ \\
\hline
\end{tabular}


Tablo 1' deki çalışmalara dair özet bilgilerde, incelenen dönem, ülke ve kullanılan istatistiksel yöntemlerde farklılıklar olduğu görülmektedir. Çalışmaların sonuçlarına bakıldığında ise; kamu harcamalarının ekonomik büyümeyi pozitif etkilediğini gösteren Verma, vd (2010), Çalışkan, vd. (2013), Arin, vd. (2015), Bekmez, vd.(2015), Ahmad, vd. (2015), Esen, vd. (2015), Başar, vd. (2016), Murthy, vd. (2016), Çalışkan, vd. (2018), Kızıl, vd. (2018)'in çalışmalarına karşılık, Yumuşak, vd.(2009), Selim, vd. (2014), Rivero (2016), Eğri (2017) gibi çalışmalarda ise kamu harcamalarının ekonomik büyüme üzerinde negatif etkili olduğu görülmektedir.

Kamu harcamaları ile ekonomik büyüme arasındaki nedenselliğin araştırıldığı Afşar (2009), Tülümce, vd. (2017), Tan, vd. (2010)'ın çalışmalarında kamu harcamaları ve ekonomik büyüme arasında çift yönlü nedensellik ilişkisi olduğu sonucu elde edilmiştir. Bu çalışmalara ek olarak Telek, vd. (2016), Abdıyeva, vd.(2017), Pamuk (2014), Kiraz, vd. (2017) ise çalışmalarında kamu harcamalarından ekonomik büyümeye doğru tek yönlü nedensellik ilişkisi olduğu sonucuna ulaşmışlardır. Çalışmaların büyük bölümünde kamu harcamaları ve ekonomik büyüme arasında farklı yönlerde ilişki bulunmasına karşılık Çetin, vd. (2010), Diler (2016), ve Kolçak, vd. (2017)'inin çalışmalarında değişkenler arasında istatistiki açıdan anlamlı bir ilişki olmadığı sonucu elde edilmiştir.

\section{Model, Veri ve Metodoloji}

Çalışmada Türkiye'de 1990-2017 yılları arasındaki dönemde kamu harcamalarının reel GSYH üzerindeki etkisinin incelenmesi amaçlanmıştır. Bu kapsamda Coub-Douglas üretim fonksiyonu çerçevesinde oluşturulan doğrusal fonksiyon dönüştürüldügünnde oluşan ampirik model şu şekildedir;

$\ln G D P_{t}=\beta_{0}+\beta_{1} \ln G O V_{t}+\beta_{2} \ln K_{t}+\beta_{3} \ln L_{t}+\beta_{4} \ln T R A_{t}+\vartheta_{t}$

Modeldeki değişkenlerden (lnGDP) doğal logaritması alınmış reel GSYH göstergesini, (lnK) doğal logaritması alınmış sermaye birikimini, (lnL) doğal logaritması alınmış emeği, (lnTRA) doğal logaritması

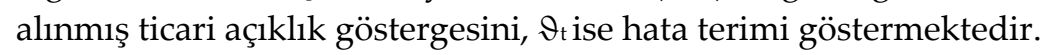

Çalışmada kullanılan veriler Dünya Bankası veri tabanından elde edilmiştir. Çalışmada ekonomik büyümeyi temsilen 2010 sabit fiyatları ve dolar üzerinden reel GSYH, sermaye birikimi için reel GSYH içindeki sermaye payından elde edilmiş kişi başına düşen sermaye miktarı, emeği temsilen toplam işgücü sayısı, ticari açılı̆̆ğ temsilen reel GSYH içindeki toplam dış ticaret oranı kullanılmıştır.

Çalışmada değişkenler arasında uzun dönem ilişki Gregory Hansen eşbütünleşme testi ve ARDL sınır testi ile araştırılmıştır. Bağımsız değişkenlerin bağımlı değişken üzerindeki kısa ve uzun dönem etkilerini tespit edebilmek için ARDL sınır testi kullanılmıştır. Ayrıca serilerin durağanlığı Ng-Perron ve Zivot-Andrews kırılmalı birim kök testleriyle araştırılmıştır.

Ng-Perron birim kök testi hataların kökü birim daireye yaklaştığında (-1'e) hatalarda meydana gelen örneklem çarpıklığının üstesinden gelebilen Perron-Ng (1996) ve Ng-Perron (2001) çalışmalarında geliştirilen M-testleridir (Sevüktekin, 2006:248). M-testleri, Philips-Perron $Z_{a}$ ve $Z_{t}$ testlerinin modifiye edilmiş hali olan $M Z_{a}$ ve $M Z_{t}$ testleri, Bhargava testinin geliştirilmişi MSB ve ADF-GLS testinin geliştirilmişi olan MPT testinden oluşan 4 farklı birim kök testidir(Göktaş, 2008:53). Ng-Perron testinde kullanılan birim kök testlerinin test istatistikleri şu şekilde hesaplanmaktadır.

$$
\begin{aligned}
& M Z_{a}=\left[T^{-1} y_{T}^{2}-s_{A R}^{2}\right]\left[2 T^{-2} \sum_{t=1}^{T} y_{t-1}^{2}\right]^{-1} \\
& M S B=\left[\frac{T^{-2} \sum_{t=1}^{T} y_{t-1}^{2}}{s_{A R}^{2}}\right]^{0,5} \\
& M Z_{t}=M S B * M Z_{a} \\
& M P T=\left[\bar{c} T^{-2} \sum_{t=1}^{T} \tilde{y}_{t-1}^{2}+(1-\bar{c}) T^{-1} \tilde{y}_{T}^{2}\right] / s_{A R}^{2}
\end{aligned}
$$

Makroekonomik zaman serileri için, uzun dönemde genellikle iktisadi şoklar ortaya çıkmaktadır. Klasik birim kök testleri, kırılmayı göz önünde bulundurmaması nedeniyle olası bir kırılma söz konusu olduğunda sonuçların hatalı olacağı ihtimalini doğurmaktadır. Ancak durağan olmayan serilerde kırılma dikkate alınırsa serilerin durağan olması ihtimali artmaktadır. Bu nedenle kırılmayı dikkate alan birim kök testleri 
geliştirilmiştir. Kırılma döneminin bilinmesi halinde kırılma dönemini dışsal olarak belirleyen testler kullanılabilmektedir. Ancak kırılma dönemi bilinmiyorsa, kırılmanın var olup olmadığını eğer var ise hangi dönemde olduğunun tespit edilmesi gerekmektedir. Kırılmanın bilinmediği ve kırılmayı içsel olarak tespit eden testlerden biri Zivot-Andrews yapısal kırılmalı birim kök testidir. Bu testin kırılmayı tespit edebilmek için kullandığ1 testler aşağıda görülmektedir(Zivot ve Andrews,1992:252: Kök Vd.,2015:159).

$y_{t}=\hat{\mu}^{A}+\hat{\theta}^{A} D U_{t}(\hat{\lambda})+\hat{\beta}^{A} t+\hat{\alpha}^{A} y_{t-1}+\sum_{j}^{k} \hat{c}_{j}^{A} \Delta y_{t-j}+\hat{e}_{t}$

$y_{t}=\widehat{\mu}^{A}+\widehat{\beta}^{B} t+\widehat{\gamma}^{B} D T_{t}^{*}(\widehat{\lambda})+\widehat{\alpha}^{B} Y_{t-1}+\sum_{j=1}^{k} \hat{c}_{j}^{B} \Delta y_{t-j}+\hat{e}_{t}$

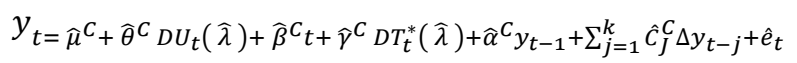

Çalışmada değişkenlerin birim kök analizlerinin yapılmasının ardından, değişkenler arasında eşbütünleşme ilişkisi tek yapısal kırılmaya izin veren Gregory-Hansen eşbütünleşme ve ARDL sınır testiyle sınanmıştır.

Tek yapısal kırılmaya imkan veren Gregory-Hansen eşbütütünleşme testinin boş hipotezi eşbütünleşmenin olmadığını öneren diğer eşbütünleşme testleri ile aynıdır. Ancak alternatif hipotezi diğer testlere göre farklıdır. Standart eşbütünleşme testleri alternatif hipotez altında eşbütünleşme vektörünün zamanla değişmediğini kabul etmekte ancak Gregory-Hansen testi geleneksel testlere karşılık vektördeki katsayıların kırılma dönemlerinde değişim yaşayabileceği fikri ile geliştirilmiştir(Gregory ve Hansen, 1996:106). GregoryHansen eşbütünleşme testinde kullanılan ADF, $Z_{a}$ ve $Z_{t}$ testleri aşağıdaki gibidir.

$Z_{\alpha}^{*}=\inf f_{\tau \in T} Z_{\alpha}(\tau)$,

$Z_{t}^{*}=i n f_{\tau \in T} Z_{t}(\tau)$,

$A D F^{*}=i n f_{\tau \in T} A D F_{(\tau)}$.

Çalışmada ayrıca, içsellik ve otokorelasyon gibi sorunlara karşı doğru ve tutarlı sonuçlar veren, değişkenler arasındaki kısa dönem uyarlama süreci ve ilişkiyi kısa ve uzun dönem olarak ayırması gibi avantajlara sahip olan ARDL sınır testi kullanılmıştır. Teste ait denklem aşağıdaki gibidir.

$$
\begin{gathered}
d \ln G D P_{t}=c_{0}+\sum_{i=1}^{n} \beta_{0} d \ln G D P_{t-i} \sum_{i=1}^{n} \beta_{1, i} d \ln G O V_{t-i}+\sum_{i=0}^{n} \beta_{2, i} d \ln K_{t-i}+\sum_{i=0}^{n} \beta_{3, i} d l L_{t-i}+ \\
\sum_{i=0}^{n} \beta_{4, i} d \ln T R A_{t-i}+\delta_{0} \ln G D P_{t-1}+\delta_{1} \ln G O V_{t-1}+\delta_{2} \ln K_{t-1}+\delta_{3} \ln L_{t-1}+\delta_{4} \ln T R A_{t-1}+\mu_{t}
\end{gathered}
$$

denklem 12 'de görülen ifadelerden $n$, gecikme sayısını, d, yapılan fark işlemini, $\delta_{1}, \delta_{2}$, $\delta_{3}$ ve $\delta_{4}$ ile ise ortak anlamlılığ sınamak için alt ve üst sınır tespit eden F-istatistiği hesaplanmaktadır. Buradan hareketle testin boş hipotezinde "eşbütünleşme yoktur", alternatif hipotezinde ise "eşbütünleşme vardır" sinanmaktadır(Destek, 2017:159). Modelde optimum gecikme uzunlukları Schwarz bilgi kriteri ile tespit edilmiştir.

Değişkenler arasındaki kısa ve uzun dönem nedensellik ilişkisi ise VECM Granger nedensellik testi ile incelenmiştir. Durağan olmayan serilere uygulanan fark işlemi, uzun dönemde mevcut değerlerin etkilenmesine neden olmaktadır. Bu noktada VECM, değişkenlerin arasındaki sahte ilişkiye imkan vermeden verilerin kısa ve uzun dönem bilgisini kullanabilmektedir. VECM durağan olmayan seriler için uygulanan fark işleminden doğan kayıpları ortadan kaldırabilmektedir(Granger 1988;556). VECM yönteminde kullanılan model ise şu şekildedir.

$(1-L)\left[\begin{array}{c}\ln G D P \\ \operatorname{lnGOV_{t}} \\ \ln K_{t} \\ \ln L_{t} \\ \operatorname{lnTRA_{t}}\end{array}\right]=\left[\begin{array}{l}a_{1} \\ a_{2} \\ a_{3} \\ a_{4} \\ a_{5}\end{array}\right]+\sum_{i=1}^{p}(1-L)\left[\begin{array}{lllll}b_{11 i} & b_{12 i} & b_{13 i} & b_{14 i} & b_{15 i} \\ b_{21 i} & b_{22 i} & b_{23 i} & b_{24 i} & b_{25 i} \\ b_{31 i} & b_{32 i} & b_{33 i} & b_{34 i} & b_{35 i} \\ b_{41 i} & b_{42 i} & b_{43 i} & b_{44 i} & b_{45 i} \\ b_{51 i} & b_{52 i} & b_{53 i} & b_{54 i} & b_{55 i}\end{array}\right]$

$X\left[\begin{array}{c}\ln G D P_{t-1} \\ \ln G O V_{t-1} \\ \ln K_{t-1} \\ \ln L_{t-1} \\ \ln T R A_{t-1}\end{array}\right]+\left[\begin{array}{c}a \\ \beta \\ \delta \\ \varphi \\ \vartheta\end{array}\right] E C T_{t-1}+\left[\begin{array}{c}\varepsilon_{1 t} \\ \varepsilon_{2 t} \\ \varepsilon_{3 t} \\ \varepsilon_{4 t} \\ \varepsilon_{5 t}\end{array}\right]$ 
13 numaralı modelde (1-L) ifadesi fark işlemcisini, $\mathrm{ECT}_{\mathrm{t}-1}$ ise $\varepsilon_{1-\mathrm{t}} \ldots \ldots \ldots . . . \varepsilon_{\mathrm{n}-\mathrm{t}}$ hata terimleri iken uzun dönemli ilişkiden elde edilen hata terimlerinin gecikmelerini ifade etmektedir. Hata terimlerinin varyansının sabit olduğu kabul edilmektedir. Uzun dönem nedensellik hata terimi katsayısının, t-istatistiğinin istatiksel bakımdan anlamlı olup olmaması ile değerlendirilmektedir. Kısa dönem nedensellik ise bağımsız değişkenin fark ve gecikmeli fark değerlerinin $x^{2}$ istatistiğine göre anlamlı olması ile değerlendirilmektedir(Yıldırım vd.,2017:105).

\section{Ampirik Bulgular}

Analizlere başlamadan önce, modeldeki değişkenlere ait tanımlayıcı istatistikler Tablo 2'de sunulmaktadır.

Tablo 2. Değişkenlere İlişkin Tanımlayıcı İstatistikler

\begin{tabular}{lccccc}
\hline & lngdp & lngov & lnk & lnl & lntra \\
\cline { 2 - 6 } Ortalama & 27.150 & 25.164 & 25.647 & 16.961 & 3.798 \\
Medyan & 27.080 & 25.111 & 25.520 & 16.912 & 3.851 \\
Maksimum & 27.818 & 25.836 & 26.581 & 17.258 & 4.006 \\
Minimum & 26.623 & 24.571 & 24.891 & 16.772 & 3.416 \\
Std.Hata & 0.365 & 0.385 & 0.558 & 0.139 & 0.168 \\
Çarpiklık & 0.270 & 0.112 & 0.226 & 0.818 & -1.128 \\
Basıklık & 1.87 & 1.80 & 1.625 & 2.50 & 3.210 \\
Gözlem Sayısı & 28 & 28 & 28 & 28 & 28 \\
\hline
\end{tabular}

Zaman serileri ile yapılan çalışmalarda, ilk olarak yapılması gereken serilerin durağanlığının tespit edilmesidir. Eğer zaman serileri durağan değilse yapılan regresyon analizleri sahte regresyon içerir. Sahte regresyon problemini ortadan kaldırmak için öncelikle serilerin bütünleşme dereceleri sınanmaktadır. Buradan hareketle çalışmada zaman serilerinin durağanlığı Ng-Perron (2001) birim kök testiyle test edilmiş elde edilen sonuçlar Tablo 3'de görülmektedir.

Tablo 3. Ng-Perron Birim Kök Testi Sonuçları

\begin{tabular}{|c|c|c|c|c|}
\hline Düzey Değerleri & $\mathrm{MZa}$ & $\mathrm{MZt}$ & MSB & MPT \\
\hline $\operatorname{lngdp}$ & 2.000 & 2.210 & 1.105 & 99.560 \\
\hline lngov & -4.512 & -1.229 & 0.272 & 5.865 \\
\hline $\operatorname{lnk}$ & 0.862 & 0.571 & 0.662 & 33.333 \\
\hline $\operatorname{lnl}$ & -1.921 & -0.756 & 0.393 & 33.888 \\
\hline lntra & -2.863 & -1.006 & 0.351 & 8.029 \\
\hline \multicolumn{5}{|l|}{ Fark Değerleri } \\
\hline$\Delta \operatorname{lngdp}$ & $-12.796^{* *}$ & $-2.500^{* *}$ & $0.195^{* *}$ & $2.024^{* *}$ \\
\hline$\Delta$ lngov & $-12.569^{* *}$ & $-2.506^{* *}$ & $0.199^{* *}$ & $1.950^{* *}$ \\
\hline$\Delta \operatorname{lnk}$ & $-12.731^{* *}$ & $-2.522^{* *}$ & $0.198^{* *}$ & $1.928^{* *}$ \\
\hline$\Delta \ln l$ & $-12.974^{* *}$ & $-2.547^{* *}$ & $0.196^{* *}$ & $1.888^{* *}$ \\
\hline$\Delta \operatorname{lntra}$ & $-12.936^{* *}$ & $-2.471^{* *}$ & $0.191^{* *}$ & $2.165^{* *}$ \\
\hline \multicolumn{5}{|l|}{ Kritik Değerler } \\
\hline$\% 1$ & -13.800 & -2.580 & 0.174 & 1.780 \\
\hline$\% 5$ & -8.100 & -1.980 & 0.233 & 3.170 \\
\hline$\% 10$ & -5.700 & -1.620 & 0.275 & 4.450 \\
\hline
\end{tabular}

Not: ${ }^{*},{ }^{* *}$ ve ${ }^{* * *}$ sirasıyla $\% 10, \% 5$ ve \%1 düzeyinde istatistiki anlamlılı̆̆g göstermektedir.

Sonuçlar serilerin tamamı için düzeyde boş hipotezin reddedilemediğini göstermektedir. Durağan olmayan seriler için fark alındığında, bütün serilerin durağan olduğu ve birinci fark değerlerinde bütünleşik oldukları görülmüştür. Ng-Perron gibi standart birim kök testleri, serilerde meydana gelen bir kırılmayı analiz dahilinde değerlendirmemektedir. Ancak kırılmalı birim kök testleri serilerde meydana gelen kırılmayı endojen olarak değerlendirilebilmektedir. Çalışmada bir yapısal kırılmaya izin veren Zivot-Andrews kırılmalı birim kök testi uygulanmış ve sonuçlar Tablo 4'de görülmektedir. 
M. Tekbaş 11/4 (2019) 2412-2424

Tablo 4. Zivot-Andrews Birim Kök Testi Sonuçları

\begin{tabular}{lcc}
\hline Düzey Değerler & $\mathrm{t}$ istatistiği & Kirllma Yılı \\
\hline lngdp & -3.742 & 1999 \\
lngov & -3.566 & 2001 \\
$\operatorname{lnk}$ & -3.551 & 1999 \\
$\ln 1$ & -2.568 & 2000 \\
lntra & -4.712 & 1994 \\
\hline Fark Değerleri & & \\
\hline$\Delta \operatorname{lngdp}$ & $-5.498^{* * *}$ & 2003 \\
$\Delta \operatorname{lngov}$ & $-6.160^{* * *}$ & 1996 \\
$\Delta \operatorname{lnk}$ & $-6.383^{* * *}$ & 2003 \\
$\Delta \operatorname{lnl}$ & $-7.185^{* * *}$ & 2008 \\
$\Delta \ln$ tra & $-5.601^{* * *}$ & 1998 \\
\hline
\end{tabular}

Not: Zivot-Andrews testi için kritik değerler: \%1:-5.34, \%5:-4.80, \%10:-4.58.

Tablo 4'de görülen Zivot-Andrews birim kök testi sonuçları incelendiğinde serilerin düzeyde durağan olmadıkları görülmekte, birinci fark değerlerine göre boş hipotez "seriler birim köklüdür" reddedilmektedir. Serilerin birinci dereceden durağan ve bütünleşik oldukları görülmüştür.

Tablo 5. Gregory Hansen Eşbütünleşme Testi Sonuçları

\begin{tabular}{lccc}
\hline & T-İstatistiği & Kırılma Dönemi & Kırılma Tarihi \\
\hline ADF & $-6.29^{* * *}$ & 18 & 2007 \\
Zt & $-6.41^{* * *}$ & 18 & 2007 \\
Za & -33.38 & 18 & 2007 \\
\hline Kritik Değerler & $\% 1$ & $\% 5$ & $\% 10$ \\
\hline ADF & -6.05 & -5.56 & -5.31 \\
Zt & -6.05 & -5.56 & -5.31 \\
Za & -70.18 & -59.40 & -54.38 \\
\hline
\end{tabular}

Birim kök testleri sonucunda, seriler I(1) bulunmuş olup, Gregory ve Hansen (1996) eşbütünleşme testi ile seriler arasındaki uzun dönem ilişki incelenmiştir. Tablo 5'de görülen Gregory-Hansen eşbütünleşme testi sonuçlarına göre, değişkenler arasında eşbütünleşmenin olmadığına işaret eden sıfır hipotezinin ADF ve Zt istatistiklerine göre reddedildiği ve eş bütünleşmenin olduğu; Za istatistiğine göre reddedilemediği görülmüştür. Ayrıca Türkiye'nin milli gelirinde önemli kırılma tarihi olarak 2007 yılı endojen olarak tespit edilmiştir. 2006 yılında meydana gelen petrol fiyatlarındaki artış ile ortaya çıkan enflasyon artışı, buna bağlı olarak cari açık da meydana gelen artış kırılmaya neden olacak ciddi gelişmeler olarak değerlendirilmektedir. Ayrıca ekonomik büyümedeki yaşanan yavaşlama ve bu ekonomik şartlar altında 2007 yılında yapılan Cumhurbaşkanlığı seçiminin de milli gelir üzerinde kırılma oluşturacak faktörler olarak değerlendirilebilir.

Tablo 6. ARDL Sınır Testi Sonuçları

\begin{tabular}{|c|c|c|}
\hline Tahmin Edien Model & Optimum Gecikme uzunluğu & F-İstatis $\breve{g} i$ \\
\hline$G P D_{t}=f\left(G O V_{t}, K_{t}, L_{t}, T R A_{t}\right)$ & $(1,0,1,1,1)$ & 16.543 \\
\hline Kritik Değerler & $I(0)$ & $I(1)$ \\
\hline$\% 1$ & 3.29 & 4.37 \\
\hline$\% 5$ & 2.56 & 3.49 \\
\hline$\% 10$ & 2.20 & 3.09 \\
\hline
\end{tabular}

Not: Kritik değerler Peseran vd. (2001), Tablo CI(iii)'den elde edilmiştir.

GDP, GOV, K, L ve TRA değişkenleri arasındaki uzun dönem eşbütünleşme ilişkisi Gregory-Hansen Eşbütünleşme testinin yanı sıra ARDL sınır testi ile sınanmış ve sonuçlar Tablo 6'da sunulmuştur. Sınır Testi 
F-istatistik sonucu 16.543 değeri, kritik değerlerle karşılaştırıldığında test üst sınırlarının üzerinde olması ile boş hipotez "eşbütünleşme yoktur" reddedilmektedir. Elde edilen F-istatistiği değerine göre değişkenler arasında uzun dönem eşbütünleşme ilişkisi olduğu görülmektedir.

Yapılan analizler neticesinde değişkenler arasında uzun dönem eşbütünleşme ilişkisinin olduğu tespit edilmiş olup, bağımsız değişkenlerin bağımlı değişken üzerinde uzun ve kısa dönemde etkilerinin yönünü ve katsayısını tahmin edebilmek üzere ARDL testi uygulanmıştır. Kısa ve uzun dönem katsayıları elde edilmeden önce yapılan teşhis testleri, Breusch-Godfrey LM testi (Serial) sonucuna göre modelde otokorelasyon sorunu olmadığı, ARCH testi sonucuna göre değişen varyans sorununun olmadığı, RamseyReset test sonucuna göre doğru fonksiyonel formun kullanıldığı ve Jargue-Bera Normalite (Normality) testi sonucuna göre hata terimlerinin normal dağılımı sahip olduğu görülmüştür. Daha sonra, Şekil 1'de görüldüğü gibi, yapılan CUSUM VE CUSUMQ testlerine göre parametrelerin istikrarlı olduğu görülmektedir.

Tablo 7'de bulunan kısa dönem sonuçlar değerlendirildiğinde kamu harcamalarının (GOV), sermaye birikiminin (K) ve emeğin (L), Türkiye'nin milli geliri üzerinde pozitif etkili olduğu, 2007 yılında meydana gelen kırılmanın (DUM07) ise milli gelir üzerinde negatif etkili olduğu, ticari açılığın (TRA) ise milli gelir üzerindeki etkisinin istatistiki açıdan anlamlı olmadığı görülmektedir. Hata düzeltme terimi (ECT) incelendiğinde, katsayının negatif ve anlamlı olduğu görülmektedir. ECT sonucuna göre Türkiye'de milli gelirde meydana gelecek bir şokun 1 yılda giderilebileceği değerlendirilmektedir.

Tablo 7. Kısa ve Uzun Dönem Katsayı Tahmincileri

\begin{tabular}{|c|c|c|c|c|}
\hline Değişken & Katsayı & Std. Hata & t-istatistiğ $\mathbf{i}$ & Olasılık \\
\hline \multicolumn{5}{|l|}{ Kısa Dönem } \\
\hline D(LNGOV) & $0.142^{* * *}$ & 0.036 & 3.925 & 0.001 \\
\hline $\mathrm{D}(\mathrm{LNK})$ & $0.281^{* * *}$ & 0.009 & 29.584 & 0.000 \\
\hline D(LNL) & $0.154^{* *}$ & 0.053 & 2.876 & 0.011 \\
\hline D(LNTRA) & 0.011 & 0.012 & 0.905 & 0.379 \\
\hline D(DUM07) & $-0.017^{* *}$ & 0.006 & -2.813 & 0.013 \\
\hline $\operatorname{ECT}(-1)$ & $-0.964^{* * *}$ & 0.105 & -9.118 & 0.000 \\
\hline \multicolumn{5}{|l|}{ Uzun Dönem } \\
\hline LNGOV & $0.363^{* * *}$ & 0.024 & 14.943 & 0.000 \\
\hline LNK & $0.305^{* * *}$ & 0.013 & 22.244 & 0.000 \\
\hline LNL & $0.537^{* * *}$ & 0.042 & 12.677 & 0.000 \\
\hline LNTRA & $0.056^{* * *}$ & 0.017 & 3.1565 & 0.006 \\
\hline DUM07 & $-0.036^{* * *}$ & 0.007 & -4.651 & 0.000 \\
\hline $\mathrm{C}$ & 0.893 & 0.517 & 1.725 & 0.105 \\
\hline Teşhis Testleri & F-istatistiği & Olasılık & & \\
\hline SERIAL & 0.615 & 0.555 & & \\
\hline $\mathrm{ARCH}$ & 0.006 & 0.934 & & \\
\hline RAMSEY & 1.476 & 0.244 & & \\
\hline JB Normalite & 1.099 & 0.577 & & \\
\hline CUSUM & İstikrarlı & İstikrarlı & & \\
\hline CUSUMQ & İstikrarlı & İstikrarli & & \\
\hline
\end{tabular}

Not : ${ }^{*}{ }^{* *}$ ve ${ }^{* * *}$ sırasıyla $\% 10, \% 5$ ve \%1 düzeyinde istatistiki olarak anlamlılığ ${ }_{1}$ ifade etmektedir. Varsayım testleri uygulanırken F-istatistiği kullanılmıştır.

Tablo 7'de bulunan uzun dönem katsayılar değerlendirildiğinde kamu harcamalarının (GOV), sermaye birikiminin (K), emeğin (L) ve ticari açıklığın (TRA) Türkiye' de reel GSYH gelir üzerindeki etkilerinin pozitif ve istatistiki olarak anlamlı olduğu, 2007 yılında oluşan yapısal kırılmanın, milli gelir üzerindeki etkisinin ise negatif ve istatistiki açıdan anlamlı olduğu görülmüştür. 


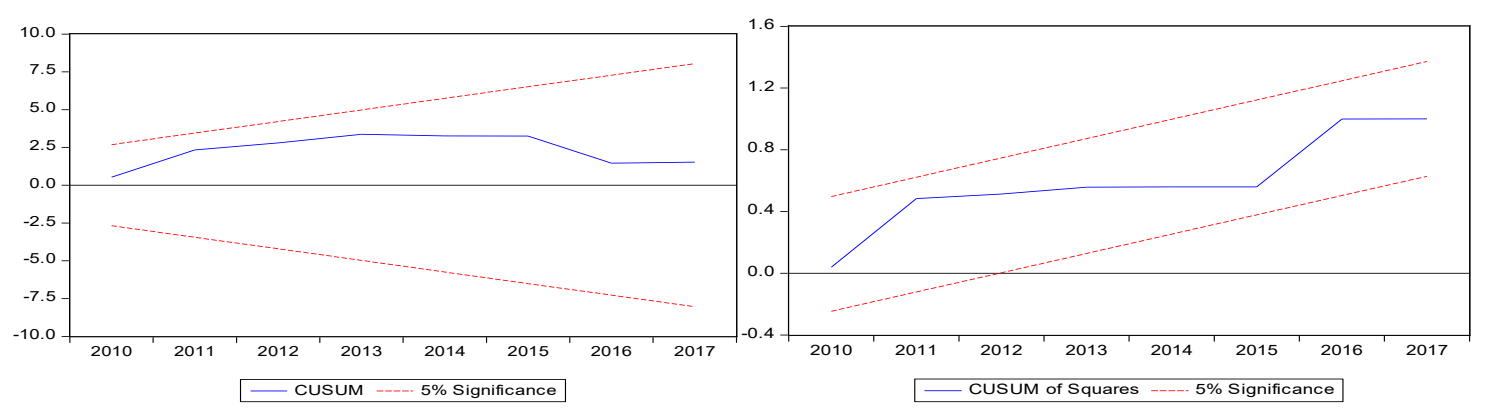

Şekil 1: CUSUM ve CUSUMQ Parametre İstikrar Testleri

Tablo 8. VECM Granger Nedensellik Testi Sonuçları

\begin{tabular}{|c|c|c|c|c|c|c|}
\hline \multicolumn{6}{|c|}{ Kısa Dönem Nedensellik } & \multirow{2}{*}{$\begin{array}{c}\text { Uzun Dönem } \\
\text { ECT (-1) }\end{array}$} \\
\hline & GDP & GOV & $\mathbf{K}$ & $\mathbf{L}$ & TRA & \\
\hline GDP & - & $\begin{array}{c}4.173 \\
(0.124)\end{array}$ & $\begin{array}{l}5.174^{*} \\
(0.075)\end{array}$ & $\begin{array}{c}10.984^{* * *} \\
(0.004)\end{array}$ & $\begin{array}{c}4.431 \\
(0.109)\end{array}$ & $\begin{array}{l}1.449^{* * *} \\
{[2.463]}\end{array}$ \\
\hline GOV & $\begin{array}{c}1.088 \\
(0.580)\end{array}$ & - & $\begin{array}{c}3.021 \\
(0.220)\end{array}$ & $\begin{array}{c}0.794 \\
(0.672)\end{array}$ & $\begin{array}{c}0.061 \\
(0.969)\end{array}$ & $\begin{array}{c}-0.097 \\
{[-0.249]}\end{array}$ \\
\hline $\mathbf{K}$ & $\begin{array}{c}1.757 \\
(0.415)\end{array}$ & $\begin{array}{l}4.624^{*} \\
(0.099)\end{array}$ & - & $\begin{array}{c}12.007^{* * *} \\
(0.0025)\end{array}$ & $\begin{array}{c}4.499 \\
(0.105)\end{array}$ & $\begin{array}{c}5.938^{* * *} \\
{[3.118]}\end{array}$ \\
\hline L & $\begin{array}{c}0.338 \\
(0.844)\end{array}$ & $\begin{array}{l}5.130^{*} \\
(0.076)\end{array}$ & $\begin{array}{c}1.674 \\
(0.432)\end{array}$ & 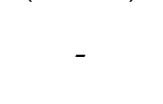 & $\begin{array}{l}7.201^{*} \\
(0.027)\end{array}$ & $\begin{array}{c}-1.045 \\
{[-3.941]^{* * *}}\end{array}$ \\
\hline TRA & $\begin{array}{c}0.695 \\
(0.706)\end{array}$ & $\begin{array}{c}1.292 \\
(0.524)\end{array}$ & $\begin{array}{c}1.147 \\
(0.563)\end{array}$ & $\begin{array}{c}1.279 \\
(0.527)\end{array}$ & , & $\begin{array}{c}2.299 \\
{[1.348]}\end{array}$ \\
\hline
\end{tabular}

Not : ${ }^{* * *},{ }^{* *} .{ }^{*}$ sirasıyla \%1, \%5 ve \%10 düzeyinde anlamlılığı ifade etmekte ve parantez içerisindeki değerler t-istatistiğidir.

Tablo 8'de VECM Granger nedensellik testi sonuçları sunulmaktadır. Kısa dönem sonuçlara göre kamu harcamaları ve ticari açıklıktan milli gelire nedensellik yoktur, sermaye birikimi ve emekten milli gelire tek yönlü nedensellik vardır. Kamu harcamalarından sermaye birikimine ve emeğe tek yönlü nedensellik, ayrıca emekten sermayeye ve ticari açıklıktan emeğe tek yönlü nedensellik olduğu görülmektedir. Uzun dönem nedensellik sonuçları değerlendirildiğinde sermaye birikimi, emek ile milli gelir arasında çift yönlü, kamu harcaması ve ticari açıklıktan milli gelire tek yönlü nedensellik olduğu görülmüştür.

\section{Sonuç}

İktisadi faaliyetlerde devletin yeri ve büyüklügünün ne olması gerektiği 1929 yılında ortaya çıkan Büyük Buhran sonrasında tekrar tartışılmaya başlanmıştır. Ekonomistler kamunun ekonomideki konumu hakkında birçok görüş ortaya koymuşlardır. Ülkelerin öncelikli hedefleri arasında ekonomik büyümeyi sağlamak, ülkelerinin refah seviyesini artırmak, yaşam koşullarını iyileştirmek gibi birçok amacı vardır. Kamu harcamaları ve ekonomik büyüme ilişkisi Wagner tarafından değerlendirildiğinde ekonomik büyümenin gerçekleşmesi neticesinde ülkede ihtiyaçlarının çeşitlenmesi ve artması nedeniyle kamu harcamalarında artış yaşanacağı yönündedir. Keynes ise kamu harcamalarını ekonomik büyümeyi sağlayan unsurlar arasında değerlendirmiş ve devletin ekonomi içerisinde etki alanının artması ile ekonomide oluşan dinamizm sayesinde ekonomik büyümenin gerçekleşeceğini savunmaktadır.

Çalışmada, 1990-2017 yılları arasındaki dönemi Türkiye için değerlendirerek kamu harcamalarının ekonomik büyüme üzerinde etkisi araştırılmıştır. Çalışmada öncelikle serilerin durağanlığı Ng-Perron birim kök testi ve serilerde oluşabilecek kırılmaları da göz önüne alan Zivot-Andrews birim kök testiyle incelenmiştir. Serilerin durağan olduğu sonucuna ulaşıldıktan sonra değişkenler arasında ilişkinin tespit edilmesi için ARDL sınır testi ve bir kırılmaya izin veren Gregory Hansen eşbütünleşme testi uygulanmıştır. Değişkenlerin kısa ve uzun dönem katsayılarının tespiti ise ARDL sınır testi ile analiz edilmiştir. Ayrıca değişkenler arasındaki nedensellik ilişkisi VECM Granger nedensellik testi ile araştırılmıştır. 
Analiz sonuçlarında elde edilen bulgulara göre, kamu harcamalarının, sermaye birikiminin ve emeğin kısa dönemde Türkiye'nin milli geliri üzerinde etkisinin istatistiki yönden anlamlı ve pozitif olduğu görülmüştür. Ticari açılığın ise milli gelir üzerinde anlamlı bir etki oluşturmadığı görülmüştür. ECT katsayısı incelendiğinde katsayının negatif ve istatistiki açıdan anlamlı olduğu ve Türkiye milli gelirinde oluşabilecek bir şokun 1 dönem gibi kısa sürede giderilebileceği sonucuna ulaşılmıştır. Ayrıca GregoryHansen testi tarafından endojen olarak belirlenen kırılma yılı 2007 yılı olduğu görülmüştür. 2007 yılında meydana gelen kırılmanın milli gelir üzerinde etkisinin negatif ve istatistiki açıdan anlamlı olduğu görülmüştür. Uzun dönemde ise, sermaye birikiminin, emeğin, ticari açılığın ve kamu harcamalarının Türkiye'de milli gelir üzerinde pozitif etkili olduğu ve 2007 yılında oluşan yapısal kırılmanın ise milli gelir üzerinde negatif etkili olduğu sonucuna ulaşılmıştır. Nedensellik testi sonucunda elde edilen bulgular, kısa dönemde kamu harcamaları ve ticari açıklıktan milli gelir doğru nedensellik ilişkisi olmadığı, sermaye birikimi ve emekten milli gelire doğru tek yönlü nedensellik ilişkisi olduğu görülmüştür. Ancak kamu harcamalarından sermaye birikimine ve emeğe doğru tek yönlü nedensellik olduğu tespit edilmiştir. Uzun dönemde ise sermaye birikimi, emek ve milli gelir arasında çift yönlü, ticari açılık ve kamu harcamalarından milli gelire doğru tek yönlü nedensellik ilişkisi olduğu sonuçlarına ulaşılmışır. Çalışmamızda elde edilen sonuçların kamu harcamalarını bütün olarak değerlendiren Verma ve Arora (2010), Arin vd. (2015), Ahmad ve Masan (2015), Esen ve Bayrak (2015), Çalışkan (2018)'ın çalışmalarıyla uyumlu olduğu, Banegas ve Rivero (2016), Artan vd. (2017)'ın çalışmaları ile uyumlu olmadığı görülmektedir.

Çalışmada kurulan model kapsamında yapılan analizlerden elde edilen sonuçlar Türkiye'de emek, sermaye, ticari açıklık ve kamu harcamalarının uzun dönemde ekonomik büyümeyi sağlayan unsurlar olduğu görülmektedir. Bu doğrultuda Türkiye'nin kamu harcamalarını emek ve sermaye birikimini destekleyecek alanlarda devam ettirmesi ekonomik büyüme konusunda olumlu katkı sağlayacağı değerlendirilmektedir. Ayrıca analizlerde uzun dönemde Türkiye'de kamu harcamalarından ekonomik büyümeye doğru nedensellik ilişkisi olduğu sonucu Keynes'in düşüncesini desteklemektedir. Bu doğrultuda kaynakların verimli ve etkin kullanılması ekonomik büyüme konusunda yarar sağlayacaktır. Bu amaçla kamu harcamalarının farklı boyutlarının ekonomik büyüme üzerindeki etkisi ayrı ayrı incelenip, elde edilen sonuçlar ışığında ekonomik büyümeye yüksek katkı sağlayacak sektörlere öncelik verilmesi önemli görülmektedir.

\section{Kaynakça}

Abdıyeva, R., \& Çetintaş, H. (2017). Kamu Harcamaları ve Ekonomik Büyüme Arasındaki İlişki: Kırgızistan Örneği. Optimum Ekonomi ve Yönetim Bilimleri Dergisi, 4(1), 19-34.

Afşar, M. (2009). Türkiye'de Eğitim Yatırımları ve Ekonomik Büyüme İlişkisi, Anadolu Üniversitesi Sosyal Bilimler Dergisi, Cilt: 9, Sayı: 1, ss. 85-98.

Ahmad, A. H., \& Masan, S. (2015). Dynamic relationships between oil revenue, government spending and economic growth in Oman. International Journal of Business and Economic Development (IJBED), 3(2), ss.93-115.

Arısoy, A. G. İ. (2005). Wagner ve Keynes hipotezleri çerçevesinde Türkiye'de kamu harcamaları ve ekonomik büyüme ilişkisi. Çukurova Üniversitesi Sosyal Bilimler Enstitüsü Dergisi, 14(2).

Arin, K. P., Braunfels, E., \& Doppelhofer, G. (2015). Taxes, Spending and Economic Growth: A Bayesian Model Averaging Approach. Cesifo WP.

Artan, S., Hayaloğlu, P., \& Demirel, S. K. (2017). Gelişmiş ve Gelişmekte Olan Ülkelerde Kamu Kesimi Büyüklüğü, Kurumsal Kalite ve Ekonomik Büyüme İlişkisi. Isletme ve İktisat Çalışmaları Dergisi, 5(3), 1-9.

Banegas Rivero, R. A. (2016). Role Of Government Spending On Economic Growth: An Endogenous Potentıal Model For Bolıvia. Revista Nicolaita de Estudios Económicos, 11(1), ss.27-48.

Başar, S., Künü, S., \& Bozma, G. (2016). Eğitim ve Sağlık Harcamalarının Ekonomik Büyüme Üzerine Etkisi: Türkiye Üzerine Bir Uygulama. Igdir University Journal of Social Sciences, (10), ss.189-204.

Bekmez, S., \& Destek, M. A. (2015). Savunma Harcamalarında Dışlama Etkisinin İncelenmesi: Panel Veri Analizi. Siyaset, Ekonomi ve Yönetim Araştırmaları Dergisi, 3(2), ss. 91-110. 
Çalışkan, Ş., Karabacak, M., \& Meçik, O. (2018). Türkiye'de Uzun Dönemde Eğitim ve Sağlık Harcamaları ile Ekonomik Büyüme İlişkisi. Dokuz Eylül Üniversitesi İktisadi ve İdari Bilimler Fakültesi Dergisi, 33(1), ss.75-96.

Çaliskan, S., Karabacak, M., \& Meçik, O. (2013). Türkiye'de Egitim-Ekonomik Büyüme Iliskisi: 1923-2011 (Kantitatif Bir Yaklasim). Çanakkale Onsekiz Mart Üniversitesi Yönetim Bilimleri Dergisi, 11(21), 29.

Çelik, O., \& Erer, E. (2018). Bireysel Emeklilik Fonları ve Cari Açık Arasındaki İlişki: Türkiye Örneği. Ege Akademik Bakış, 18(2), 289-305.

Çetin, M., \& Ecevit, E. (2010). Sağlık harcamalarının ekonomik büyüme üzerindeki etkisi: OECD ülkeleri üzerine bir panel regresyon analizi. Doğuş Üniversitesi Dergisi, 11(2), ss.166-182.

Destek, M. A., Okumuş, İ., \& Manga, M. (2017). Türkiye'de finansal gelişim ve gelir dağı̆lımı ilişkisi: Finansal kuznets eğrisi. Doğuş Üniversitesi Dergisi, 18(2), ss.153-165.

Diler, H. (2016). Kamu Harcamaları-Ekonomik Büyüme: Türkiye Üzerine Bir Uygulama. İktisat Politikası Araştırmaları Dergisi, 3(1), 21-36.

Durmuş, S. (2017). Eğitim Harcamalarının Ekonomik Büyüme Üzerine Etkisi: Ampirik Bir Çalışma. Finans Politik \& Ekonomik Yorumlar, 54(629), 9-18.

Eğri, T., Timur, B., Eğri, C. Ö., \& Bayraktar, Y. (2017). Seçilmiş Ortadoğu Ülkeleri için Ekonomik Büyüme ve Savunma Harcamaları İlişkisi: Panel Veri Analizi. Research Journal of Politics, Economics \& Management/Siyaset, Ekonomi ve Yönetim Arastirmalari Dergisi, 5(5).

Erdoğan, S., \& Yıldırım, D. Ç. (2009). Türkiye'de eğitim-iktisadi büyüme ilişkisi üzerine ekonometrik bir inceleme. Bilgi Ekonomisi ve Yönetimi Dergisi, 4(2), ss.11-22.

Esen, Ö., \& Bayrak, M. (2015). Kamu Harcamaları ve Ekonomik Büyüme İlişkisi: Geçiş Sürecindeki Türk Cumhuriyetleri Üzerine Bir Uygulama. Bilig/Türk Dünyası Sosyal Bilimler Dergisi, (73), ss.231-248.

Giray, F. (2004). Savunma Harcamalari ve Ekonomik Büyüme. Cumhuriyet Üniversitesi İktisadi ve İdari Bilimler Dergisi, 5(1), 181-199.

Göktaş, Ö. (2008). Türkiye Ekonomisinde Bütçe Açığının Sürdürülebilirliğinin Analizi. Ekonometri ve İstatistik e-Dergisi, (8), 45-64.

Granger, C. W. (1988). Causality, cointegration, and control. Journal of Economic Dynamics and Control, 12(2-3), 551-559.

Gregory, A. W., \& Hansen, B. E. (1996). Residual-based tests for cointegration in models with regime shifts. Journal of econometrics, 70(1), 99-126.

Hayaloğlu, P., \& Bal, H. Ç. (2015). Üst orta gelirli ülkelerde sağlık harcamaları ve ekonomik büyüme ilişkisi. İşletme ve İktisat Çalışmaları Dergisi, 3(2), ss.35-44.

Kar, M., ve Taban, S. (2003). Kamu harcama çeşitlerinin ekonomik büyümeye etkisi. Ankara Üniversitesi SBF Dergisi, 58(3), 159-175.

Kızıl, B. C., \& Ceylan, R. (2018). Sağllk Harcamalarının Ekonomik Büyüme Üzerine Etkisi: Türkiye Örneği. Journal of Yasar University, 13(52), ss.197-209.

Kiraz, H., \& Gümüş, E. (2017). Kamu Harcamalarının Büyümeye Etkisi: OECD Ülkeleri Üzerine Bir Araştırma. Finans Politik \& Ekonomik Yorumlar, 54(631), 9-22.

Kolçak, M., Kalabak, A. Y., \& Boran, H. (2017). Kamu Harcamaları Büyüme Üzerinde Bir Politika Aracı Olarak Kullanılmalı mı? VECM Analizi ve Yapısal Kırılma Testleri ile Ampirik Bir Analiz: 1984-2014 Türkiye Örneği. Ankara Üniversitesi SBF Dergisi, 72(2), 467-486.

Kök, R., Ekinci, R., \& Yalçınkaya, A. E. A. (2015). Ülke riski bileşenlerinin bankacilık ve reel sektör üzerine etkileri: Türkiye örneği, 1993-2015. Çukurova Üniversitesi İktisadi ve İdari Bilimler Fakültesi Dergisi, 19(2), 151-171.

Murthy, V. N., ve Okunade, A. A. (2016). Determinants of US health expenditure: Evidence from autoregressive distributed lag (ARDL) approach to cointegration. Economic Modelling, 59, 67-73.

Pamuk, M., \& Bektaş, H. (2014). Türkiye'de eğitim harcamaları ve ekonomik büyüme arasındaki ilişki: ARDL sınır testi yaklaşımı. Siyaset, Ekonomi ve Yönetim Araştırmaları Dergisi, 2(2), ss.77-90.

Pesaran, M. H., Shin, Y., \& Smith, R. J. (2001). Bounds testing approaches to the analysis of level relationships. Journal of applied econometrics, 16(3), 289-326.

Selim, S., Uysal, D., \& Eryiğit, P. (2014). Türkiye'de sağlık harcamalarının ekonomik büyüme üzerindeki etkisinin ekonometrik analizi. Ömer Halisdemir Üniversitesi İktisadi ve İdari Bilimler Fakültesi Dergisi, 7(3), 13-24. 
Sevüktekin, M., \& Nargeleçekenler, M. (2006). İstanbul Menkul Kıymetler Borsasında Getiri Volatilitesinin Modellenmesi Ve Önraporlanması. Ankara Üniversitesi SBF Dergisi, 61(4), 243-265..

Tan, B. K., Merter, M., \& Özdemir, Z. A. (2010). Kamu yatırımları ve ekonomik büyüme ilişkisine bir bakış: Türkiye, 1969-2003. Dokuz Eylül Üniversitesi İktisadi ve İdari Bilimler Fakültesi Dergisi, 25(1), ss.2539.

Telek, C., \& Telek, A. (2016). Kamu Harcamaları Ve Ekonomik Büyüme İlişkisinin Wagner Ve Keynes Hipotezi Çerçevesinde İncelenmesi. Uluslararası Yönetim İktisat ve İşletme Dergisi, 30, 628-642.

Verma, S., ve Arora, R. (2010). Does the Indian Economy Support Wagner s Law? An Econometric Analysis. Eurasian Journal of Business and Economics, 3(5), 77-91.

Yaraşır Tülümce, S., \& Zeren, F. (2017). Türkiye'de Kamu Harcamaları Ve Ekonomik Büyüme Arasındaki İlişkinin Asimetrik Nedensellik Testi İle Analizi. Uluslararası Yönetim İktisat ve İşletme Dergisi, 13(2), 299-310.

Yıldırım, M., Destek, M. A., \& Özsoy, F. N. (2017). Doğrudan Yabancı Yatırımlar Ve Kirlilik Sığınağı Hipotezi. Cumhuriyet Üniversitesi İktisadi ve İdari Bilimler Dergisi,18(2),99-111

Zivot, E., \& Andrews, D. W. K. (2002). Further evidence on the great crash, the oil-price shock, and the unit-root hypothesis. Journal of business \& economic statistics, 20(1), 25-44. 